TẠP CHÍ KHOA HỌC ĐẠI HỌC TÂN TRÀO

ISSN: 2354 - 1431

http://tckh.daihoctantrao.edu.vn/

\title{
Yếu tố bản địa trong hoa sắt trang trí kiến trúc Hà Nội thời Pháp thuộc
}

\author{
Đinh Quang Mạnh ${ }^{a^{*}}$ \\ ${ }^{a}$ Trưòng Đại học Tân Trào \\ *Email:manhsptq@gmail.com
}

\section{Thông tin bài viết}

Ngày nhận bài:

29/01/2018

Ngày duyệt đăng:

$10 / 3 / 2018$

\section{Tù khoá:}

Hoa sắt; kiến trúc bản địa; trang tri kiến trúc;kiến trúc Hà Nội thời Pháp thuộc.

\begin{abstract}
Tóm tắt
Hệ thống đồ án hoa sắt trong các thành phần kiến trúc là một trong những thành tố quan trọng góp phần tạo nên diện mạo kiến trúc Hà Nội thời Pháp thuộc. Trong khoảng thời gian không dài từ cuối thế kỷ XIX đến nửa đầu thế kỉ $\mathrm{XX}$, hoa sắt với tính chất bền chắc và những mỹ cảm riêng có toát lên từ chất liệu đã song hành cùng sự phát triển các xu hướng kiến trúc tại Hà Nội thời kỳ này, tạo nên một hiện tượng mỹ thuật đặc sắc: thấm đẫm tinh thần truyền thống bản địa trên nền các giá trị phương Tây.
\end{abstract}

Từ cuối thế kỷ XIX đến nửa đầu thế kỉ XX, với mục tiêu đưa Hà Nội thành thủ phủ hành chính của xứ Bắc Kỳ và thủ đô của Liên bang Đông Dương, chính quyền thực dân Pháp đã tập trung nỗ lực mở rộng Hà Nội, đồng thời đẩy mạnh xây dựng những công trình kiến trúc tại đây và một số địa phương khác ở Việt Nam. Thời gian này chính là một trong những thời điểm quan trọng đánh dấu bước chuyển mình của nghệ thuật kiến trúc Việt Nam từ truyền thống sang hiện đại. Kiến trúc phương Tây, bằng những con đường du nhập khác nhau, đã vào Việt Nam như: "Thông qua các nhà truyền bá Thiên chúa giáo", "Thông qua các nhà cố vấn về xây dựng thành lũy", thông qua "quá trình thiết lập ách thống trị thực dân và đô hộ" và "bằng con đường đào tạo kiến trúc sư ở Trường Cao đẳng Mỹ thuật Đông Dương" [13;15]. Trải qua thời gian, với những diễn biến văn hóa có tính quy luật, kiến trúc Pháp từ sự phô trương, áp đặt ban đầu đã dần dần "chuyển hóa mềm mại và có đặc trưng phù hợp với đặc điểm tự nhiên và nhân văn Hà Nội" [8]. Các trào lưu, phong cách, trường phái kiến trúc của phương Tây, của Pháp và sau đó là ảnh xạ của nền kiến trúc trên, trên cơ sở tiếp biến với nghệ thuật bản xứ, đã nối tiếp nhau xuất hiện tại Hà Nội cũng như tại nhiều nơi khác ở Việt Nam, như phong cách kiến trúc Tiền thực dân, Tân cổ điển, địa phương Pháp, Art Deco, Đông Dương... Giờ đây, nhiều công trình kiến trúc thời Pháp thuộc ở phía Bắc Việt Nam, đặc biệt là ở Hà Nội, đã trở thành những di sản mang nhiều giá trị.

Một trong những thành tố quan trọng góp phần tạo nên những nét đẹp riêng của kiến trúc Hà Nội thời Pháp thuộc đó là hệ thống đồ án hoa sắt trong các thành phần kiến trúc như cổng, hàng rào, cửa sổ, cửa đi, ô thoáng, ban công, tay vịn cầu thang.... Trong khoảng thời gian không dài với những khúc quanh của lịch sử, hoa sắt với tính chất bền chắc và những mỹ cảm riêng có toát lên từ chất liệu đã song hành cùng sự phát triển các xu hướng kiến trúc tại Hà Nội thời kỳ này, tạo nên một hiện tượng mỹ thuật đặc sắc: thấm đẫm tinh thần truyền thống bản địa trên nền các giá trị phương Tây.

Yếu tố bản địa trong hoa sắt trang trí kiến trúc tại Hà Nội thời Pháp thuộc là những hoa sắt mà trong đó, ở những mức độ khác nhau, được sáng tạo trên cơ sở những mô típ trang trí truyền thống hoặc gợi lên dấu ấn truyền thống Việt Nam. Những mô típ trang trí truyền thống đó bao gồm cả những mô típ có nguồn gốc bản địa và những mô típ có nguồn gốc từ các nền văn hóa khác như Ấn Độ, Trung Quốc du nhập vào Việt Nam, trải qua quá trình biến thiên lâu dài của lịch sử đã được bản địa hóa. 
Qua khảo sát thực tế, bước đầu chúng tôi nhận thấy yếu tố bản địa trong hoa sắt trang trí kiến trúc tại Hà Nội thời Pháp thuộc được biểu hiện theo một số cách thức và xu hướng khác nhau.

\section{Diễn đạt lạihoa văn trang trí truyền thống}

Diễn đạt lại những hoa văn trang trí truyền thống bằng chất liệu sắt thanh như: hoa văn chữ Thọ, hoa văn chữ Phúc, hoa văn chữ Vạn, hoa văn kết thừng, hoa văn vân mây, sóng nước, hoa văn đồng tiền... Dưới đây là một số ví dụ cụ thể.

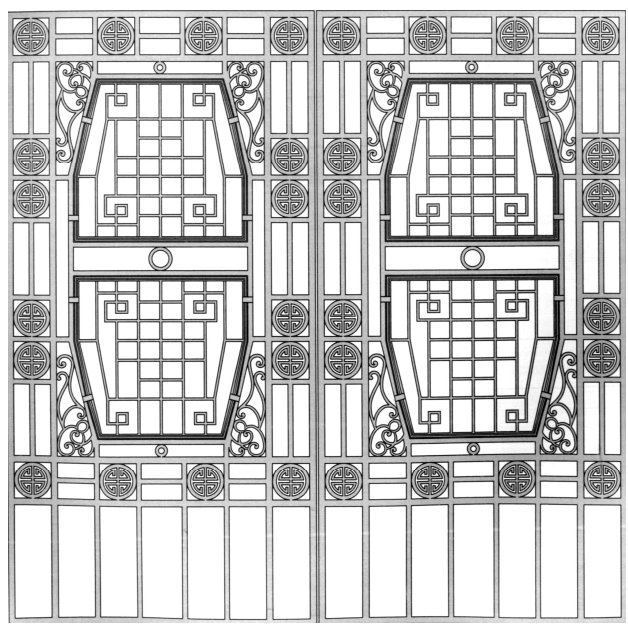

Hình 1: Cổng sắt nhà số 26 phố Phan Bội Châu $[12 ; 52]$

Cổng Dinh thự số 26 Phố Phan Bội Châu (Hình 1) sử dụng hoa văn chữ Thọ lớn đặt ở vị trí trung tâm, xung quanh cũng là các hoa văn chữ Thọ có kích thước nhỏ được xắp xếp nhắc lại có quy luật theo phương dọc và ngang,giới hạn bằng những thanh phân vị dọc và ngang tạo thành hệ thống diềm bo xung quanh hai cánh cổng.

Dinh thự số 14 Đường Thành sử dụng nhiều đồ án trang trí chữ Thọ, đồng tiền. Trên cổng chính toà nhà, hoa văn chữ Thọ lớn được tạo tác theo hình vuông và hình tròn đặt ở vị trí trọng tâm. Trên cửa đi vào tầng hai của căn nhà, chấn song được tổ hợp từ ba chữ Phúc - Lộc - Thọ. Một mô típ hoa văn khác được sử dụng nhiều trên cổng đó là hoa văn đồng tiền. Thoạt nhìn, những hoa văn này giống như những bông hoa bốn cánh có lỗ vuông ở chính tâm, tuy nhiên, khi liên hệ với hoa văn đồng tiền được đúc trên hàng rào và các ô cửa kính liên phòng trong nhà thì không khó để nhận ra, đây chính là một dạng biến điệu của hoa văn đồng tiền. Hệ thống hoa văn trang trí nói trên thể hiện ước vọng giàu sang may mắn của người Á Đông. (Hình 2a,b)

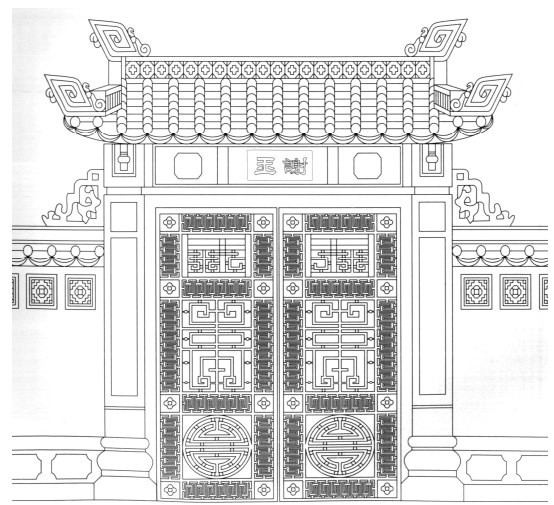

Hình 2a: Cổng dinh thụ số 14 phố Đuòng Thành $[12 ; 53]$

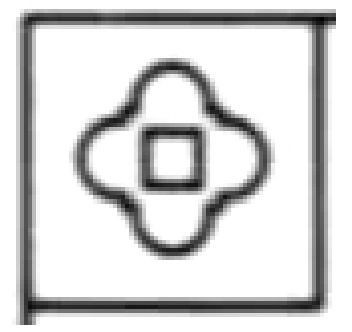

Hình 2b: Chi tiết hoa văn đồng tiền trên cổng dinh thư 14 phố Đưòng Thành [12;53]

Biệt thự số 86 phố Thụy Khuê - trên cổng sắt có ghi khánh thành năm 1925 - là biệt thự 3 tầng mang phong cách kiến trúc Đông Dương nhưng hình khối kiến trúc và đặc biệt là phần mái nhà mang phong cách Cổ điển Pháp. Trán cổng được tạo tác hình một chiếc khánh, một trong những mô típ trang trí truyền thống biểu tượng cho sự chúc tụng, niềm vui, hoan hỉ.

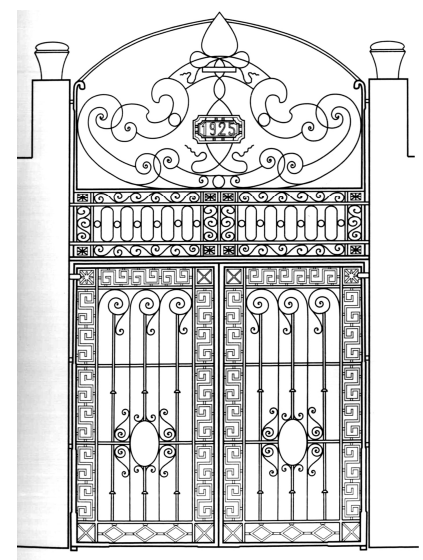

Hình 3: Cổng nhà số 86 phố Thụy Khuê [12;109]

\section{Kết hợp những mô típ trang trí truyền thống} với những mô típ trang trí có nguồn gốc phương Tây

Sự kết hợp giữa truyền thống bản địa và phương Tây thường được thể hiện trên cùng một đồ án trang trí hoặc trong một không gian kiến trúc, một công 
trình kiến trúc. Một vài công trình kiến trúc đưới đây có những trang trí theo kiểu kết hợp này.

Đền thờ Lê Lợi tại số 16 phố Lê Thái Tổ là một trong những công trình kiến trúc kết hợp hai truyền thống bản địa và phương Tây khá đặc biệt. Công trình ngôi đền này được Kinh lược sứ khởi công từ năm 1896 với mục đích tâm linh là thờ vua Lê Thái Tổ. Trong đền thờ, bức tượng vua Lê mặc áo long cổn, đầu đội mũ Bình thiên được đặt trang trọng trên một bệ tròn cao hình trụ kiểu thức cổ điển phương Tây; chiếc cổng mang đậm phong cách truyền thống với 13 đồ án chữ Thọ kiểu thức tròn, trong đó một chữ Thọ lớn ở vị trí trung tâm, nhưng phần đỉnh 2 cột của cánh cổng chính lại sử dụng hoa văn cách điệu từ hoa Bách hợp (Tiếng Pháp: Fleur-de-lis ) với phần đuôi của 2 cánh phình to và cuộn xoắn ốc. Phần thắt dây được người thợ khéo léo rèn phình to. Đây được coi là một trong những hình cách điệu hoa bách hợp độc đáo nhằm mục đích tạo ra sự hài hòa giữa chi tiết hoa trang trí với tổng thể kiến trúc. Công trình đền thờ Lê Lợi là một hiện tượng văn hóa độc đáo, mà ở đó, có sự hòa trộn một cách hợp lý giữa các truyền thống Việt Nam và phương Tây. Ngoài ra, đây cũng có thể coi là một biểu hiện văn minh của những người xây dựng công trình trong việc ứng xử một cách đầy thành kính với một nhân vật lịch sử, anh hùng giải phóng dân tộc của người Việt (Hình 4)
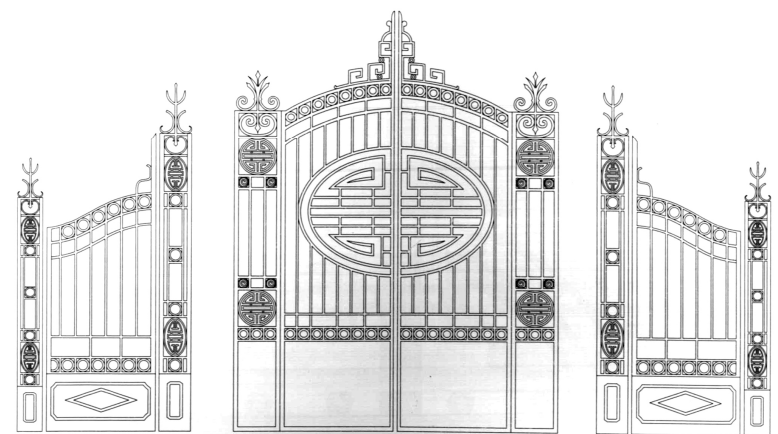

Hình 4: Cổng vào Đền thò̀ Lê Lợi tại số 16 phố Lê Thái Tổ [12;108]

Biệt thự số 8 Phố Chân Cầm được thiết kế theo phong cách Đông Dương, hệ thống song của sổ sử dụng mô típ trang trí hình đồng tiền có nguồn gốc phương Đông. Trong khi đó, phần lan can cầu thang và cổng rào lại sử dụng họa tiết phương Tây với lối bố cục mang phong cách Tân cổ điển. Ngoài ra, đỉnh các cột cổng cũng được tạo tác mô phỏng phần trên cột kiểu thức Korinth có nguồn gốc Hy Lạp. (Hinh 5)

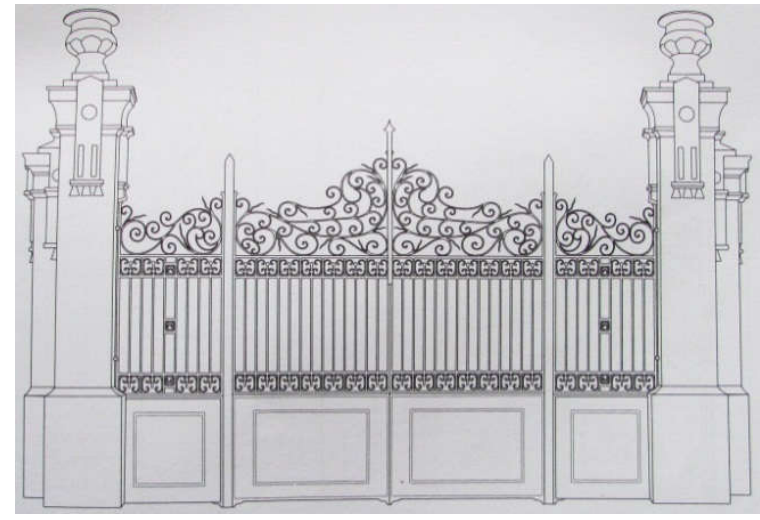

Hình 5: Biệt thự số 8 phố Chân Cầm [12;115]

Nhà số 19 Nguyễn Biểu là kiểu biệt thự kiểu Pháp đặc trưng phong cách phương Tây, sử dụng hệ thống hoa sắt điển hình phương Tây. Tuy nhiên phần đỉnh cột cổng lại có hình búp sen, một mô típ trang trí truyền thống tiêu biểu ở Việt Nam biểu tượng cho đức hạnh và sự hoàn hảo. (hinh 6$)$

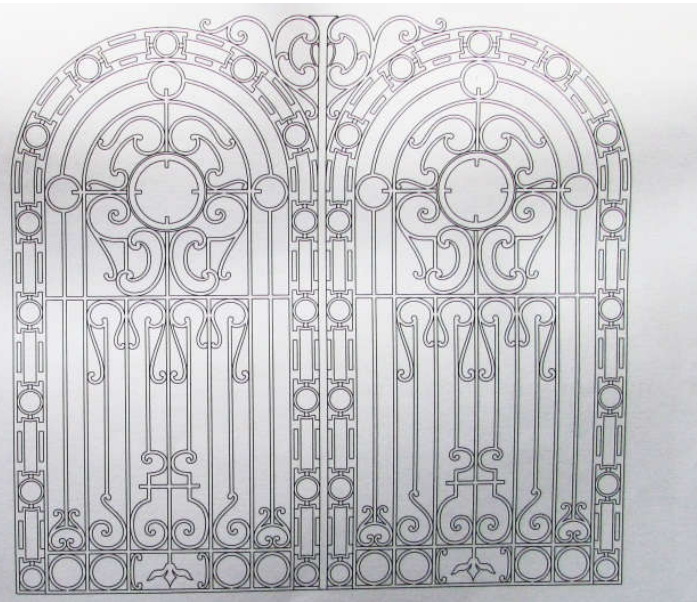

Hình 6: Cổng biệt thư số 19 phố Nguyễn Biểu[12;105]

Cửa đi nhà số 317 phố Thụy Khê là sự kết hợp các mô típ hoa văn trang trí lá Ô rô (Acanthus) với những mô típ trang trí truyền thống như con dơi, cuốn thư. Trong nghệ thuật trang trí cổ điển phương Tây, hoa văn lá Ô rô là một trong những hoa văn điển hình, biểu tượng cho tầng lớp quý tộc. Đối với trang trí truyền thống Việt, hoa văn dơi là một dạng thức biểu hiện của chữ Phúc với ý nghĩa của sự may mắn, hạnh phúc; cuốn thư là biểu tượng của học thức, trí tuệ - người Việt có truyền thống hiếu học, những người có học thường được coi là tầng lớp tinh hoa trong xã hội, đứng đầu Sĩ, Nông, Công, Thương vì vậy học thức và trí tuệ mặc nhiên đại diện cao nhất cho sự sang trọng. Sự kết hợp những mô típ hoa văn trên thể hiện mong ước thành đạt 
trên con đường học vấn, giàu sang và hạnh phúc của chủ nhân của ngôi nhà.

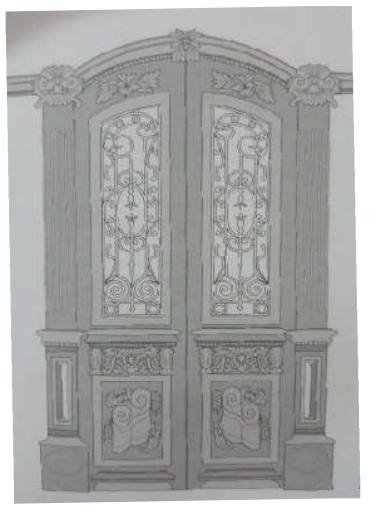

Hình 7: Của đi nhà số 317 phố Thụy Khê [12;143]

3.Sử dụng những mô típ và họa tiết trang trí của mỹ thuật bản địa để tạo nên những họa tiết và những đồ án trang trí theo nguyên lý tạo hình hiện đại của phương Tây

Do ảnh hưởng của sự phát triển của phong cách nghệ thuật Art Nouveau, Art Deco ở châu Âu, nhiều kiến trúc sư người Pháp đã đưa các yếu tố của 2 phong cách nghệ thuật được coi là hiện đại lúc bấy giờ tại Pháp vào trong công trình mà họ thiết kế ở Việt Nam. Các bộ phận và chi tiết trang trí Art Nouveau, Art Deco dần dần được Việt Nam hoá ở những mức độ nhất định. Bên cạnh các hình hoa lá kiểu Châu Âu, xuất hiện một hoặc nhiều những chi tiết trang trí lấy cảm hứng từ các hoạ tiết, hoa văn truyền thống Việt Nam. Điều này cho thấy, sau một thời gian sống và làm việc ở Việt Nam, các kiến trúc sư người Pháp đã tìm hiểu khá kỹ kiến trúc truyền thống bản địa. Và, trong quá trình thiết kế các bộ phận và chi tiết trang trí theo phong cách Art Nouveau, Art Deco, họ đã đưa vào khá nhiều yếu tố kiến trúc bản địa và chính sự kết hợp tinh tế giữa hai nền văn hóa Á - Âu như vậy đã tạo ra được những hoa văn và đồ án trang trí độc đáo. Xin dẫn ra đây một vài ví dụ.

Cổng nhà số 72 và 76 phố Trần Quốc Toản được làm theo phong cách Art Deco sử dụng các chất liệu hình tượng phương Đông điển hình. Trong đó, hoa văn chủ đạo được sử dụng là hoa văn cuộn xoắn đơn dạng thức hình tròn. Dạng đồ án này cho ta liên tưởng đến hoa văn trang trí trên gốm và đồ đồng Đông Sơn. Trên trán cổng phần kết thúc là dạng thức hoa văn con triện, xoắn ốc vuông xuất hiện nhiều trên trang trí truyền thống. Đồ án trang trí theo dạng này cũng xuất hiện nhiều trên những phố Trần Hưng Đạo, Lê Văn Hưu, Ngô Văn Sở, Hàng Chuối, Trần
Xuân Soạn, Phố Huế, Lê Duẩn, Thi Sách..., chủ yếu là những công trình nhà ở được làm sau năm 1930 có quy mô nhỏ. Các hoạ tiết được sử dụng một cách tiết chế tạo cảm giác nhẹ nhàng nhưng tinh tế từ sự sắp đặt hoa văn cho đến sự trau chuốt trên từng chi tiết. (Hình 8a, hình 8b).

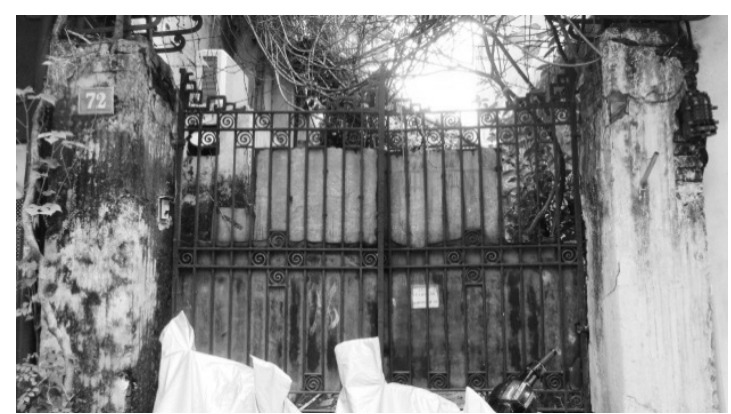

Hinh 8a:Cổngbiệt thụ số 72 phố Trần Quốc Toản

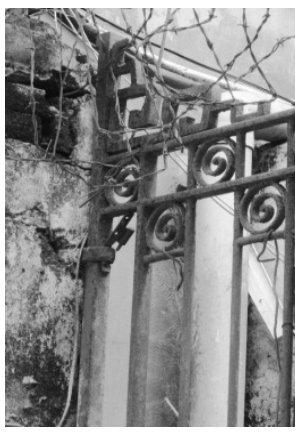

Hình 8b: Chi tiết trên cổng biệt thư số 72 phố Trần Quốc Toản

Trên cổng của nhà số 59 phố Trần Hưng Đạo có mảng đồ án vân mây sóng nước được tạo hình rất hiện đại, không giống với những dạng thức trang trí kiến trúc của các trường phái Cổ điển, Baroque, Tân cổ điển từng xuất hiện trước đó ở Hà Nội. Phần chính của cổng có lồng hai chữ $\mathrm{M}$ và $\mathrm{C}$. Giữa mảng tiếp giáp hai chữ $\mathrm{M}$ và $\mathrm{C}$ này là mảng nhắc lại hoa văn vân mây sóng nước - một mô tip trang trí điển hình trong mỹ thuật truyền thống.(Hinh 9)

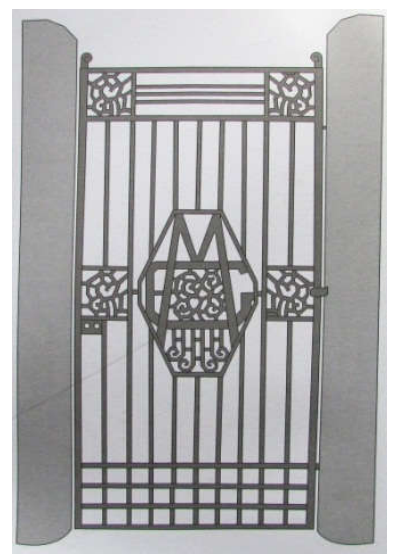

Hìn 9: Cổng biệt thư số 59 phố Trần Hung Đạo [12;126] 
Nhà số 38 phố Tăng Bạt Hổ có một chiếc cổng khá đặc biệt. Các dạng thức hoa văn được sử dụng xuyên suốt đồ án đó là hoa văn vân xoắn ốc đơn tròn dạng "Đông Sơn", dạng thức hoa văn đường xiên chéo như là một góc của một hình tượng phát sáng tạo ra những tia. Ở chính giữa là sự nhắc lại của sáu tổ hợp hoa văn dạng dây leo cấu trúc hình ôval, chính giữa hình ôval này là một hình chữ nhật vê tròn bốn cạnh, từ đây chia ra bốn đường tỏa về bốn góc, các đường này kết thúc bằng một họa tiết vân xoắn đơn nội tiếp hình vuông trước khi phát triển theo phương dọc thành tổ hợp hoa văn mới. Hình ôval có "nhân" tỏa ra bốn góc này gợi cảm giác về những biểu tượng phát sáng trong trang trí truyền thống. (Hình 10)
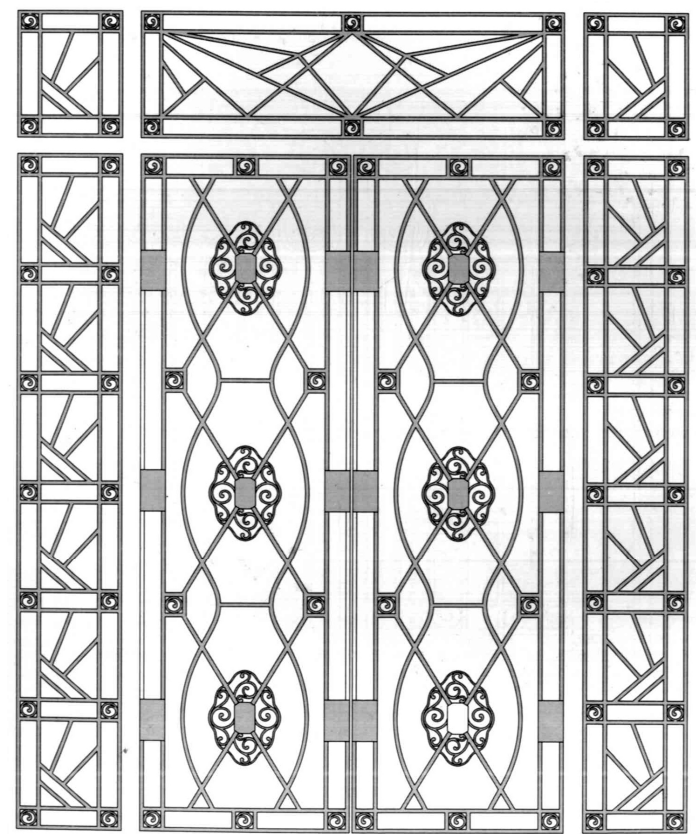

Hinh 10: Cổng sắt biệt thụ số 38 phố Tăng Bạt Hổ $[8 ; 127]$

\section{Hoa văn và đồ án hoa văn được sáng tạo trên co sở nắm bắt "cái thần" của trang trí truyền thống}

Nắm bắt cái thần của trang trí truyền thống - "cái thần nói đây là một cái gì bao trùm, là thể tổng hòa của những quan niệm, những quan điểm, những thái độ của cả một lớp người, trong cả một thời, trước xã hội, trước đồng loại, trước thiên nhiên, trước cái Đẹp" (Nguyễn Đức Nùng; 1978)[10;49] - sáng tạo, thể hiện nó để rồi được cảm nhận bằng những tín hiệu phát ra thông qua những biểu tượng; đồng thời thông qua những ý niệm nằm sâu trong tâm tưởng người thưởng lãm mà nhận ra sự quen thuộc của truyền thống ẩn chứa trong đó. Đây là một cách thức sáng tạo cao, đòi hỏi chủ thể sáng tạo phải là người nghiên cứu rất kỹ di sản truyền thống, chiêm nghiệm, tổng hợp, vượt lên trên sự kết hợp đơn lẻ để tạo ra một liên tưởng siêu hình.

Cổng nhà số 14 Phố Thi Sách (Hinh 11) sở hữu một bộ cửa và hàng rào mang phong cách Art Deco sử dụng mô típ chủ đạo vân xoắn đơn nội tiếp hình tròn, điều này gợi liên tưởng đến vòng tròn âm dương với phần nét của thanh kim loại (dương) kết hợp với phần rỗng (âm). Tổng thể chiếc cổng là hình chữ nhật đứng được phân thành ba tuyến theo phương ngang. Ba tuyến này phân định chiếc cổng thành ba phần trên dưới và phần giữa được định hình bằng hai cột gạch xây dày dặn, chắc khỏe ít họa tiết, tạo tương phản với phần cánh với những hoa văn nhỏ dày. Tuyến trên của phần cánh là sự nhắc lại liên tục của bốn tổ hợp hoa văn vân xoắn đơn kết hợp với một số hoa văn hình chữ $\mathrm{S}$ nằm ngang, giữa mỗi tổ hợp hoa văn lại có một hoa văn vân xoắn đơn nằm xen kẽ. Các họa tiết hoa văn được xắp xếp theo quy tắc cách một họa tiết đơn là một khoảng rỗng tiếp tục bằng họa tiết đơn; định hình bằng các nan thẳng ngang và dọc. Sự xắp xếp này tạo nên các cặp phạm trù đối lập mang đậm triết lý Á Đông: có - không, đặc rỗng, âm - dương, tinh - không...

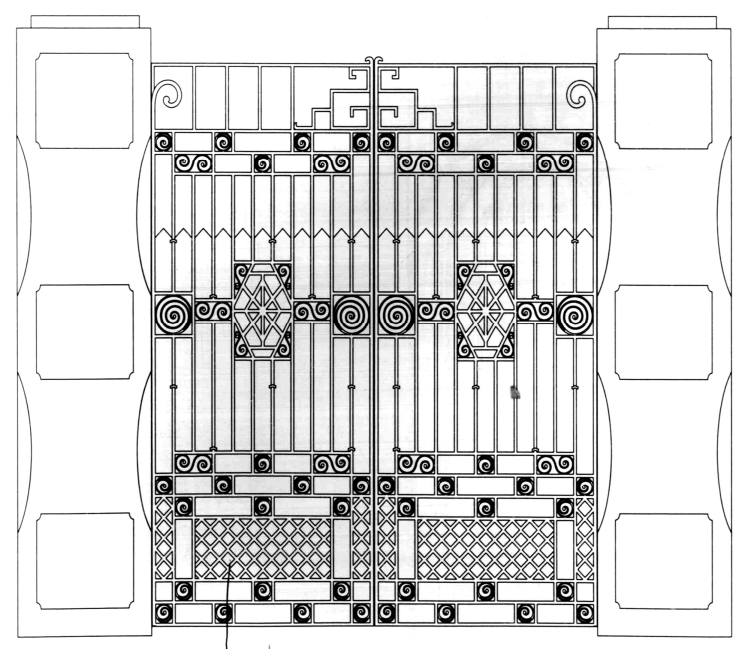

Hình 11: Cổng nhà số 14 phố Thi Sách [12;112]

Nghệ thuật trang trí kim loại trong kiến trúc Hà Nội thời Pháp thuộc được phát triểntrên cơ sở tiếp nối $\mathrm{xu}$ hướng sử dụng kim loại trang trí của phương Tây đương thời, và theo thời gian nó va đập, dung hội, khúc xạ, biến đổi và bung tỏa trên nền tảng cơ tầng của một nền văn hóa bản địa lâu đời, giàu bản sắc;mặt khác, phong cách kiến trúc Đông Dương ra đời như là ảnh xạ của quá trình giao lưu tiếp biến văn hoá Đông Tây, "phản ánh nét ứng xử với các hệ thống giá trị ngoại lai đã được bản địa hóa, bị khúc xạ trong môi trường văn hóa Việt" [12;30]; thêm vào đó, là lớp kiến trúc sư đầu 
tiên người Việt Nam tốt nghiệp trường Mỹ thuật Đông Dương mang trong mình tinh thần dân tộc sâu sắc. Tất cả những điều đó đã tạo nên sự đa dạng, phong phú về hình thức và chủng loại hệ thống hoa văn, trong đó hoa văn mang dấu ấn bản địa nổi lên như một điểm sáng và là một trong những minh chứng sắc nét cho tâm hồn, trí tuệ, bản lĩnh văn hóa Việt Nam trong quá trình giao lưu, tiếp xúc với văn hóa phương Tây.

\section{TÀI LIẸU THAM KHẢO}

1. Henry R. D Allemagne, Decorative Antique Ironwork (Dover Jewelry and Metalwork), Dover Publications, New York, 2009;

2. Trần Quốc Bảo, Nguyễn Văn Đỉnh, Kiến trúc và quy hoạch Hà Nội thời Pháp thuộc, Nxb Xây dựng, Hà Nội, 2012;

3. Miranda Bruce, Mitford, Signs and Symbols, Schiffer Publishing, Ltd, 2008;

4. Trần Lâm Biền, Trang trí trong mỹ thuật truyền thống của người Việt, Nxb Văn hóa dân tộc, Hà Nội, 2001;

5. Trần Lâm Biền, Trịnh Sinh, Thế giới biểu tượng trong di sản văn hóa Thăng Long - Hà Nội, Nxb Hà Nội, Hà Nội, 2011;

6. Jean Chevalier, Alain Gheerbrant, Dictionary of Symbols, Penguin Books, Lon Don, 1997;

7. Đặng Thái Hoàng, Kiến trúc Hà Nội thế kỷ XIX XX, Nxb Hà Nội, Hà Nội, 1985;
8. Trần Nhật Khôi, Giá trị của các công trình kiến trúc Pháp tại Hà Nội, Tạp chí xây dựng số 6, 2007 ;

9. Ana M. Lopez, Metalworking through History: An Encyclopedia (Handicrafts through World History), Greenwood, Lon Don, 2009;

10. Nhiều tác giả, Nghiên cưu mỹ thuật, Viện Mỹ thuật Hà Nội, 1992;

11. Phan Phương Thảo, Khu phố Tây ở Hà Nội nủa đầu thế kỷ XX qua tu liệu địa chính, Nxb Hà Nội, Hà Nội, 2017;

12. Trần Hậu Yên Thế, Song xua phố cũ và nhũng ghi chép bên lề, Nxb Thế giới, Hà Nội, 2013;

13. Nguyễn Đình Toàn, Nhũng nhân tố tụ nhiên và truyền thống văn hóa bản địa trong kiến trúc thòi Pháp thuộc ở Việt Nam, LATS kỹ thuật, chuyên ngành kiến trúc nhà ở và công trình công cộng, 1998;

14. Trung tâm lưu trữ Quốc gia 1, Kiến trúc các công trình xây dựng tại Hà Nội (1875 - 1945), Nxb Thế giới, Hà Nội, 2014;

15. Trường Đại học Mỹ thuật Việt Nam - Viện Mỹ thuật, Nghệ thuật trang trí cổng làng Hà Nội nưa đầu thế kỷ $X X$, Tạp chí Nghiên cứu Mỹ thuật, (số tháng 12), tr $86-87,2012$;

16. Trần Quốc Vượng, Nguyễn Chí Bền, Tô Ngọc Thanh, Lâm Mỹ Dung, Trần Thúy Anh, Co sở văn hóa Việt Nam, Nxb Giáo dục, Hà Nội, 2002.

\section{Native aspects in decorative ironwork of Hanoi architecture in the period of French domination}

Dinh Quang Manh

\section{Article info}

Recieved:

29/01/2018

Accepted:

$10 / 3 / 2018$

Keywords:

Decorative ironwork; native aspects; decorative architecture;

Hanoi architecture in French domination.

\begin{abstract}
Decorative ironwork in architecture components is one of important aspects that contribute to forming the appearance of Hanoi architecture in the period of French domination. In the period of second half of 19 century to the first half of 20 century, Decorative ironwork with lasting and artistic characteristics, had been parallel with the development of architecture trends in Hanoi. This had created a special phenomenon of art which imbued the native traditional spirit with the foundation of Western values.
\end{abstract}

